\title{
Effect of Temperature and phase transformation on the Characteristics of Al-Mg alloy.
}

\author{
R.H.Nada*, H.Y.Zahran, M.M. Mostafa, M.M.El-Sayed and F.Fahim \\ Physics Department, Faculty of Education, Ain Shams University, Roxy, \\ Cairo, Egypt
}

Samples of Al-5wt.\%Mg alloy used as sheets, for internal friction $Q^{-1}$, dynamic elastic modulus $Y$ and wires for stress-strain measurements, were heated at $823 \mathrm{~K}$ for 2 hours then one group of the samples was slowly furnace cooled to room temperature and the second group was rapidly quenched in iced water. Both groups were tested in the temperature range from $493 \mathrm{~K}$ to $553 \mathrm{~K}$ in steps of $10 \mathrm{~K}$. The sheets were aged for 2 hours at different temperatures then quenched in iced water. $Q^{-1}$ and the dynamic Young's modulus, $Y$ measurements by applying resonance technique were obtained at room temperature. The wires used for stress-strain measurements were tested in the working temperature range, and the yield stress $\sigma_{y}$ at different temperatures was obtained. The Vickers hardness, $H_{v}$, was obtained from its relation to $\sigma_{y}$. Increasing temperature $Q^{-1}$ increased showing abrupt increase at $523 \mathrm{~K}$, while $Y$ and $H_{v}$ decreased showing minima at $523 \mathrm{~K}$. Above $533 \mathrm{~K}, Q^{-1}$ increased, while $Y$ and $H_{v}$ decreased. This behavior indicated a thermal softening in the tested range; structure measurements disclosed phase transformation from $(\alpha+\beta)$ phases into the single $\alpha$-phase at $523 K$. The quenched samples showed higher hardness levels than the slowly cooled samples due to the presence of excess point defects and their interaction with dislocations. The activation energy values were 17.33 and $59.184 \mathrm{~kJ} / \mathrm{mol}$ before and after transition, respectively. The microstructure of the aged slowly cooled samples examined by $X$-ray diffraction measurements supported the phase transformation at $523 \mathrm{~K}$.

\section{Introduction}

During material's lifetime it may undergo plastic deformation several times, either during processing of a product to a given shape or in use. Thus, an ideal material should have a low resistance to forming and a high resistance to undesirable deformation during use. Plastic deformation occurs by three main types of mechanisms: sliding of grain boundaries, diffusion of vacancies and the motion of lattice dislocations [1]. 
The addition of Magnesium to aluminum provides considerable strengthening through a combination of solute hardening and strain hardening. $\mathrm{Mg}$ in solid solution increases the deformation resistance of aluminum.

Al-Mg alloys are used in automotive body structures, trains, shipbuilding or cryogenic vessels, civil and military applications, helicopter decks, containers and tanks for storing or transportation of liquid gases. Al-Mg alloys play an important role in engineering applications, due to their excellent mechanical and electrical properties. This was improved by adjusting the contents of doped elements, analyzing the effect of intermetallic phases and raising the surface coating $[2,3]$.

Al- Mg alloys containing more than $3 \mathrm{wt} . \% \mathrm{Mg}$ become susceptible to stress corrosion cracking due to super- saturation of solid solution and increased tendency of $\mathrm{Mg}$ atoms to precipitate at grain boundaries as high anodic $\beta$ - phase $\left(\mathrm{Mg}_{5} \mathrm{Al}_{18}\right)[4,5]$.

The precipitation is accelerated by heating at temperature $\left(80-160{ }^{\circ} \mathrm{C}\right)$ or after very long aging at room temperature. Experimentally the observed aging sequence in Al-Mg alloys is [6,7], supersaturated $(\alpha)$ solid solution $\rightarrow$ guinier preston (G.P. zones) $\rightarrow \beta^{\prime \prime} \rightarrow \beta^{\prime} \rightarrow \beta$, phases.

It was suggested [6] that the G.P. zones formed during the quenching process or after aging the $\mathrm{Al}-\mathrm{Mg}$ alloy at low temperatures act as nuclei for the precipitates.

According to the constitutional phase diagram of Al-Mg system[8] given in Fig.(1), the solid solubility of $\mathrm{Mg}$ in $\mathrm{Al}$ increases with temperature and reaches the maximum value $17.4 \mathrm{wt} \%$ at the eutectic temperature, $450^{\circ} \mathrm{C}$. The equilibrium $\beta-\mathrm{Al}_{13} \mathrm{Mg}_{2}$-phase has a fcc structure with the lattice parameter $\mathrm{a}=2.8239 \mathrm{~nm}$ and the space group $\mathrm{Fd} 3 \mathrm{~m}[9]$.

The present work aims to study the effect of heat treatment and phase transformation on the structural and mechanical properties of $\mathrm{Al}-\mathrm{Mg}$ alloy.

\section{Experimental procedures.}

\subsection{Sample preparation}

The material used in the present work is Al-5356 alloy received from Alcotec wire company- USA in the form of wires $0.5 \mathrm{~mm}$ in diameter and 
sheets $0.2 \mathrm{~mm}$ in thickness. The full details of preparation of $\mathrm{Al}-5 \mathrm{wt} . \% \mathrm{Mg}$ alloy used in this study have been published elsewhere [10]. The sheets and wires were heated at $823 \mathrm{~K}$, for two hours then a group of samples was slowly cooled to room temperature with a cooling rate of $1.2 \times 10^{-2} \mathrm{~K} / \mathrm{s}$ to obtain the mixed $(\alpha+\beta)$ phases and the samples become fully precipitated, as clear from the phase diagram of Fig.(1).

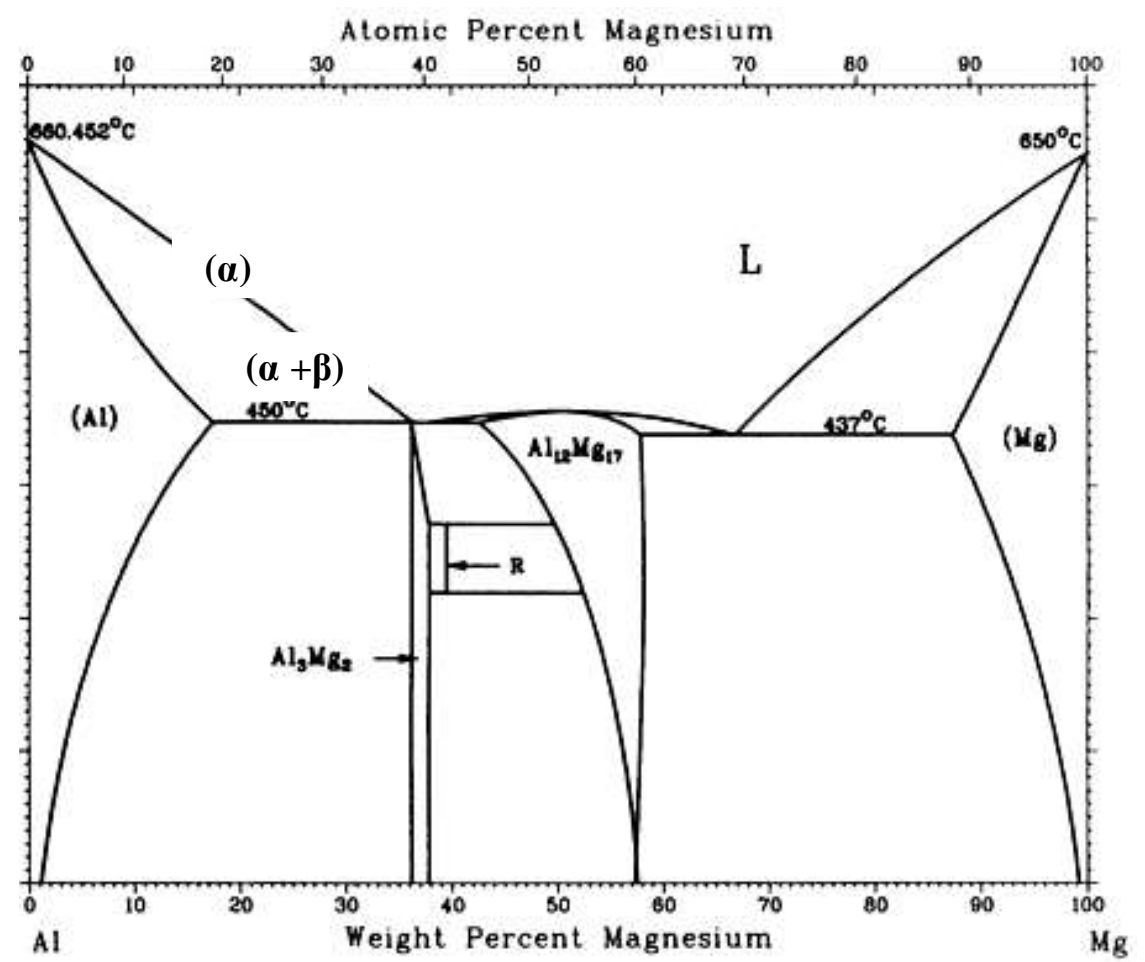

Fig. (1): The equilibrium phase diagram of Aluminum- magnesium alloy.

The second group of samples was rapidly quenched from $823 \mathrm{~K}$ in cold water kept at $273 \mathrm{~K}$ to obtain samples with supersaturated $\alpha$-solid solution structure [8].

The slowly cooled and the quenched samples were heated at temperatures in the range from $493 \mathrm{~K}$ to $553 \mathrm{~K}$ in steps of $10 \mathrm{~K}$, for two hours. 


\subsection{Mechanical Measurements}

Measurements of internal friction $\mathrm{Q}^{-1}$ and dynamic elastic modulus $\mathrm{Y}$ for preaged samples were carried out at room temperature by applying the dynamic resonance technique based mainly on the theory of free vibration of solid bodies by using the device used elsewhere [11]. The experimental arrangement, procedure, and measuring techniques with the following equations are published elsewhere [12].

$$
\operatorname{Tan} \delta=\mathrm{Q}^{-1}=\Delta \mathrm{F} / \sqrt{ } 3 \mathrm{~F}_{0}=0.5773 \Delta \mathrm{F} / \mathrm{F}_{0}
$$

where $\tan \delta$ is the mechanical loss $\Delta \mathrm{F} / \mathrm{F}_{0}, \Delta \mathrm{F}$ is the full width at half maximum amplitude, $\mathrm{F}_{0}$ is the resonance frequency, and

$$
(\mathrm{Y} / \mathrm{d})^{1 / 2} \mathrm{~K} / 2 \pi=\mathrm{L}^{2} \mathrm{~F}_{0} / \mathrm{Z}^{2}
$$

where $\mathrm{d}$ is the density of the sample under test, $\mathrm{L}$ is the length of the vibrating part of the sample, $\mathrm{K}$ is the radius of gyration of the cross section about the axis perpendicular to the plane of vibration and $\mathrm{Z}$ is constant depending on the mode of resonance. For the fundamental mode of resonance $\mathrm{Z}$, assumes the value $1.875[13]$.

Stress-stain curves were obtained by using tensile testing machine described elsewhere [14] for the slowly cooled and quenched samples of the tested alloy under the same working temperature. The applied stress was gradually increased, with $30 \mathrm{~s}$ interval between two successive loadings. The elongation was measured by a dial gauge with sensitivity of $\pm 10^{-5} \mathrm{~m}$.

The yield stress, $\sigma_{y}$, considered as the stress corresponding to the first significant deviation from linearity in the starting part of the stress-strain curve at different temperatures.

Hardness, H, measurement as a handy tool is related, in several alloy systems, with other mechanical parameters such as the yield stress $\sigma_{y}$, which is intimately related to $\mathrm{H}$ and typically, $\mathrm{H}=3 \sigma_{\mathrm{y}}$, in bulk metals [15] which shows that the temperature dependence behavior of hardness, $\mathrm{H}$, will be similar to that of yield stress, $\sigma_{\mathrm{y}}$ obtained from stress-strain results obtained under the same conditions. The temperature dependence of hardness was reported as [16].

$$
\mathrm{H}=\mathrm{H}_{\mathrm{o}} \exp (-\alpha \mathrm{T})
$$

where $\mathrm{H}_{\mathrm{o}}$ is the intrinsic hardness at $0 \mathrm{~K}$, and $\alpha$ is the softening coefficient or the coefficient of thermal expansion.

\subsection{Structural measurements}


The microstructure of the slowly cooled samples of Al-5wt.\% $\mathrm{Mg}$ alloy heated for two hours in the temperature range from $493 \mathrm{~K}$ to $553 \mathrm{~K}$ in steps of $10 \mathrm{~K}$ was identified using a Philips $\mathrm{X}$ - ray diffractometer (PW 1050), with $\mathrm{Cu}$ $\mathrm{K}_{\alpha}$ radiation $(\lambda=0.1542 \mathrm{~nm})$ and scan speed adjusted at $5^{\circ}$ min $^{-1}$ in the angle range $2 \theta$ from $20^{\circ}$ up to $90^{\circ}$.

\section{Experimental results and discussion.}

On heating the slowly cooled samples which comprise the mixed phases $(\alpha+\beta)$ below $523 \mathrm{~K}$, these phases coarsen and may dissolve a bit due to the increase of the solid solubility of the $\beta$-phase $(\mathrm{Mg})$ in the matrix to attain the equilibrium composition. This process proceeds by diffusion which causes recovery that requires the movement of dislocations at the interphase boundaries and reflects the competition between the effect of dynamic recovery and the effect of solute drag and precipitation hardening which takes place during plastic flow of these materials [17]. By aging the quenched samples, which have the metastable structure of the single $\alpha$ - phase solid solution, blew $523 \mathrm{~K}$

the $\beta$ - phase $(\mathrm{Mg})$ starts to precipitate and the structure of the alloys starts to transform into the double mixture $(\alpha+\beta)$ phases, whose amount depends on both the aging temperature and the aging time. The order of the inhomogeneous solid solution formed at the transformation temperature $523 \mathrm{~K}$, in both samples, is destroyed by plastic deformation leading to the marked decrease of $\mathrm{Q}^{-1}$ and the increase of the $\mathrm{Y}$ and $\mathrm{H}_{\mathrm{v}}$ Fig.(4). These marked variations at $523 \mathrm{~K}$ might be also attributed to the increased solid solubility of $\beta$-phase in the matrix at this transformation temperature [18].

The X-ray diffraction patterns of the slowly cooled Al-5wt. $\% \mathrm{Mg}$ samples heated at different temperatures from $493 \mathrm{~K}$ to $553 \mathrm{~K}$ are given in Fig.(2). It is clear that all the obtained patterns indicate polycrystalline structure.

XRD cards used to identify the patterns, whose analysis is given in Table (1), as representative example for $493 \mathrm{~K}$ sample, consist with the equilibrium phase diagram, shown in Fig.(1) which characterizes the phases existing at certain temperature for a given composition at equilibrium. Below the transformation temperature $523 \mathrm{~K}$ the analysis of the patterns disclose the formation of the intermediate phases, $\mathrm{Al}_{3} \mathrm{Mg}_{2}, \mathrm{Al}_{2} \mathrm{Mg}, \mathrm{Al}_{12} \mathrm{Mg}_{17}$ and $\mathrm{Al}$ as hard inclusions in the system, leading to high degree of disorder with more hardness than that at the transformation temperature where $\mathrm{Al}$ and the intermediate phase $\mathrm{Al}_{12} \mathrm{Mg}_{17}$, exist[19]. After transformation the double phase becomes single phase and the tested samples show lower levels of hardness than those before transformation. 


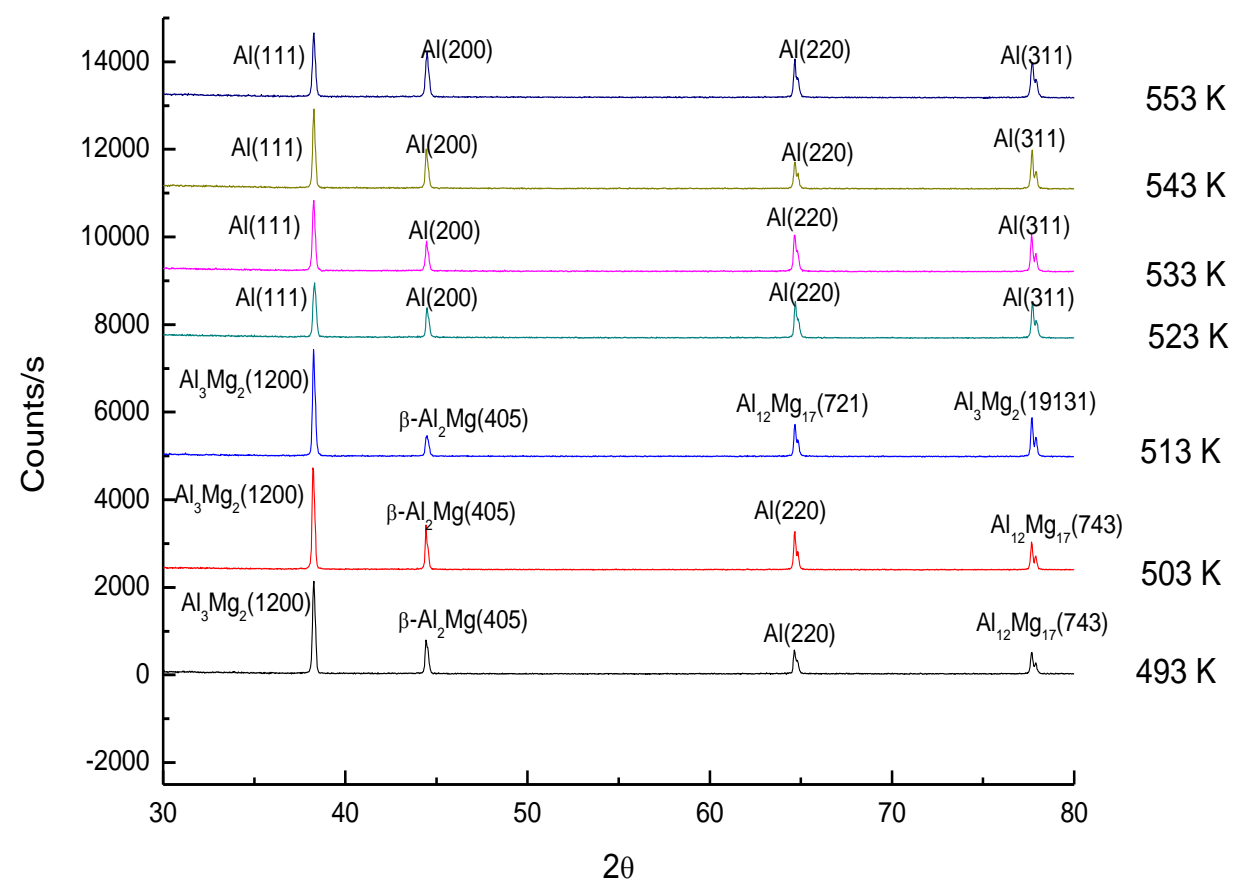

Fig. (2): X-ray Diffraction patterns of slowly cooled for Al-5wt. \% Mg samples at different aging temperature.

Table 1, Representative example for X-rays data of $493 \mathrm{~K}$

\begin{tabular}{|c|c|c|c|c|}
\hline Peak no. & $\mathbf{2 \theta}$ & d(obs.) & d (cal.) & phase \\
\hline $\mathbf{1}$ & 38.25099 & 2.35101 & 2.353 & $\mathrm{~A} 13 \mathrm{Mg} 2$ \\
\hline $\mathbf{2}$ & 44.417211 & 2.03789 & 2.03 & ß-Al2Mg \\
\hline $\mathbf{3}$ & 64.8399 & 1.44083 & 1.4348 & $\mathrm{~A} 112 \mathrm{Mg} 17$ \\
\hline $\mathbf{4}$ & 77.90168 & 1.22529 & 1.2256 & $\mathrm{~A} 112 \mathrm{Mg} 17$ \\
\hline $\mathbf{5}$ & 82.06898 & 1.17329 & 1.1736 & $\mathrm{~A} 13 \mathrm{Mg} 2$ \\
\hline
\end{tabular}

Fig.3(a,b) shows the relation between the values of the resonance frequency $(F)$ and the amplitude (A) for both the slowly cooled and the quenched samples of AL-5wt. $\% \mathrm{Mg}$ alloy at different aging temperatures. In general, it's clear that increasing temperature above $493 \mathrm{~K}$ decreases the levels of amplitude. Irregular arrangement is observed at $523 \mathrm{~K}$ pointing to the state of the transformation taking place at $523 \mathrm{~K}$ above which continuous decrease of the amplitude levels takes place. The irregular shift of the peaks and levels of the curves of Fig.(3) can be attributed to the effect of aging temperature. 

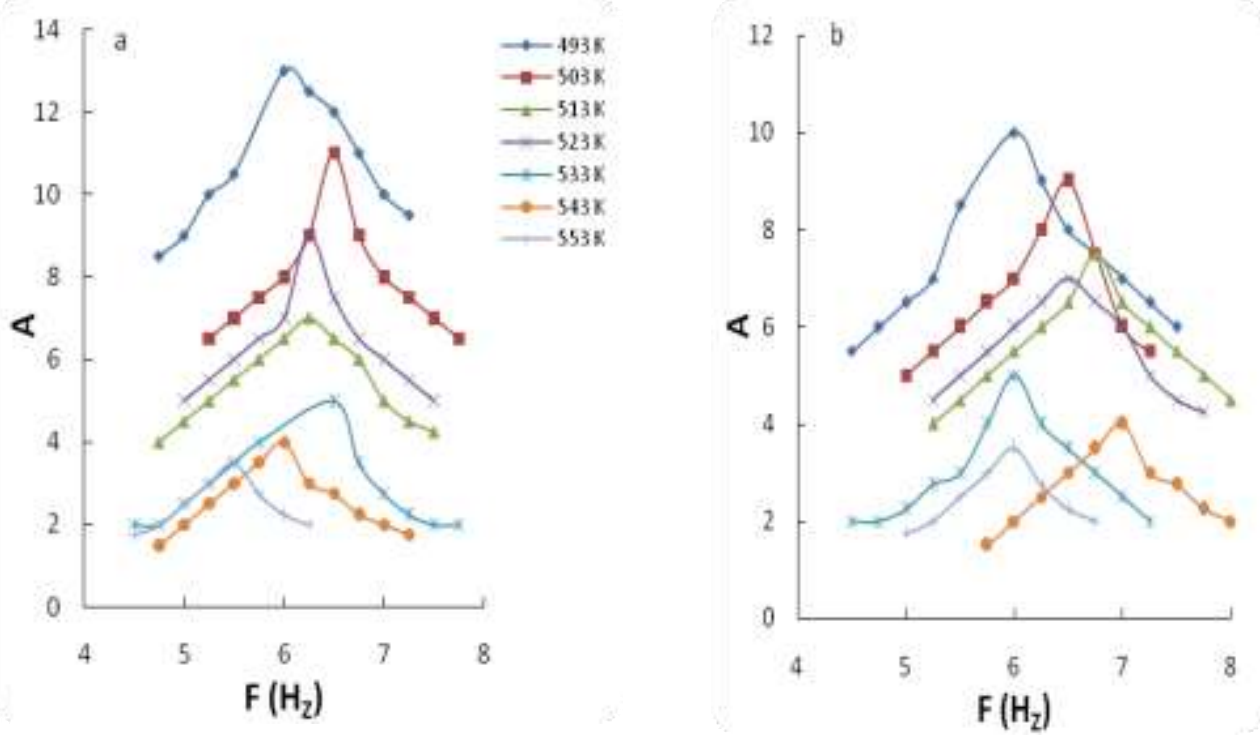

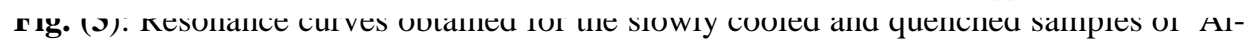
$5 \mathrm{wt} . \% \mathrm{Mg}$ at different temperatures.

The temperature dependence the internal friction $\mathrm{Q}^{-1}$, and the dynamic elastic modulus Y, calculated from equations 1, 2, and Fig.(3) for both alloy samples is shown in Fig.4(a,b). The temperature dependence of Vickers microhardness $\mathrm{H}_{\mathrm{v}}$, deduced from $\sigma_{\mathrm{y}}$ values obtained from the stress - strain curves, shown in Fig.5(a,b), for both samples is given in Fig.(4c). The dynamic elastic modulus $\mathrm{Y}$, Vickers microhardness $\mathrm{H}_{\mathrm{v}}$ decreases with increasing aging temperature, reaching a minimum value at $523 \mathrm{~K}$ then showed an increase up to $533 \mathrm{~K}$ followed by continuous decrease and in general, the quenched samples have higher values than the slowly cooled samples. Fig.(4a) shows that the internal friction $\mathrm{Q}^{-1}$ increases with increasing aging temperature and exhibit abrupt values at $523 \mathrm{~K}$. Also, the slowly cooled samples have higher $\mathrm{Q}^{-1}$ values than the quenched samples. The increase in $\mathrm{Q}^{-1}$ values Fig.(4a) for slowly cooled and quenched samples up to $523 \mathrm{~K}$ correspond to a increase in $\mathrm{Y}$ and $\mathrm{H}_{\mathrm{v}}$ values, due to the softening effect of thermal agitation which increased the density of mobile dislocations.

The level of dynamic elastic modulus $\mathrm{Y}$ and the Vickers microhardness $\mathrm{H}_{\mathrm{v}}$ of the quenched samples is higher than of the slowly cooled samples. This may be due to the existence of excess quenched-in vacancies in a supersaturated state. This leads to that a hardening interaction with: moving dislocations, short and long ranges, chemical, elastic or electrostatic and Snoek 
ordering. Heating these quenched samples at temperatures below $523 \mathrm{~K}$ gives rise to a very fine structure with very high dislocation density [20].
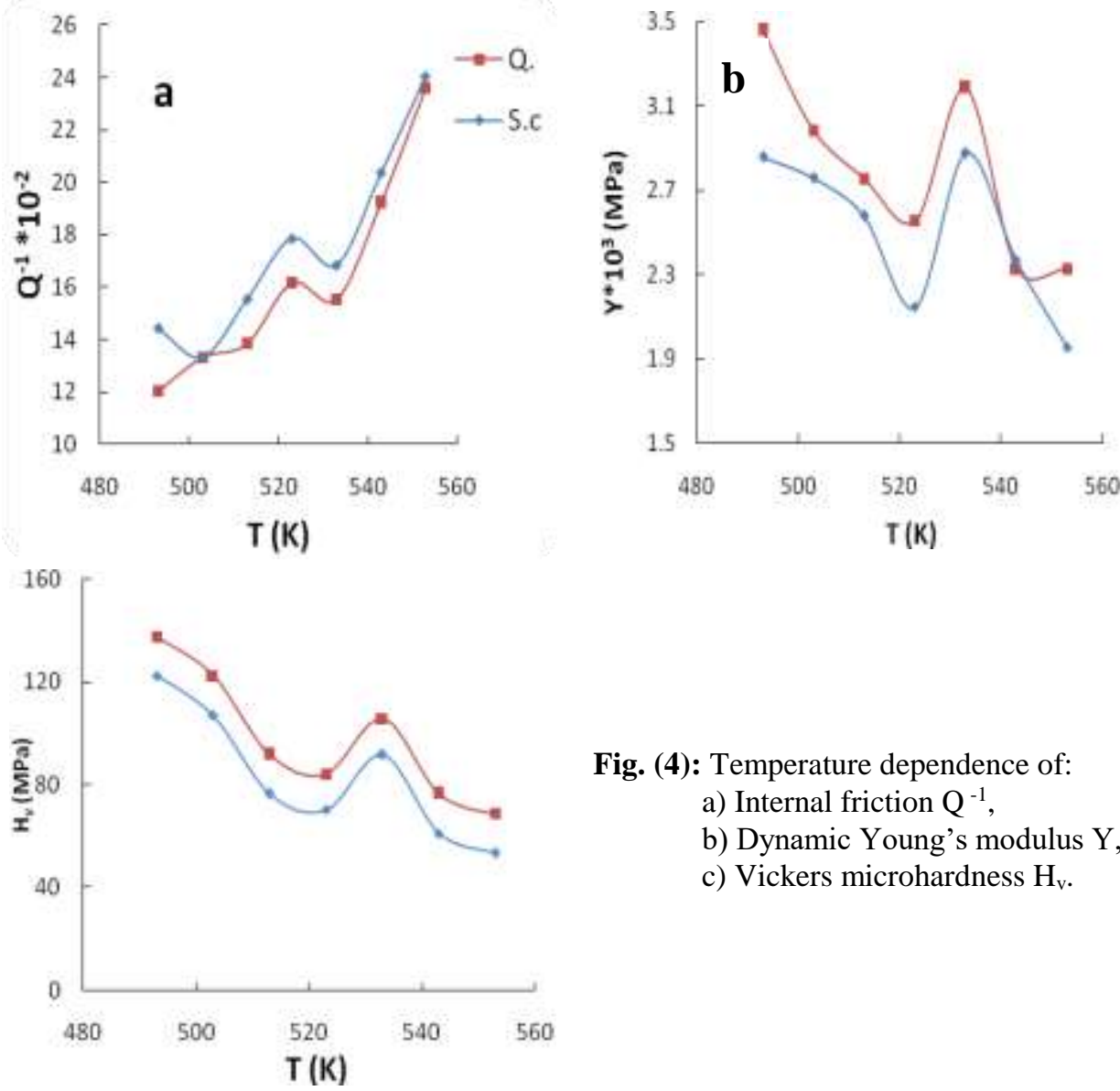

Fig. (4): Temperature dependence of:

a) Internal friction $Q^{-1}$,

b) Dynamic Young's modulus Y,

c) Vickers microhardness $\mathrm{H}_{\mathrm{v}}$

The initial values of the double phase $(\alpha+\beta)$ is the highest values of dynamic elastic modulus $\mathrm{Y}$ and Vickers microhardness $\mathrm{H}_{\mathrm{v}}$ in the low temperature in the range from $493 \mathrm{~K}$ to $523 \mathrm{~K}$, Fig. $(4 \mathrm{~b}, \mathrm{c})$, may be due to the formed hard phase of inter - metallic compounds removing The dissociation of the unstable and vacancy clusters increases the number of dislocations pinning points which harden the matrix and reduces internal friction $\mathrm{Q}^{-1}$, Fig.(4a) and increases the microhardness $\mathrm{H}_{v}$ Fig.(4c) and couses the irregularity of the amplitude curves of Fig. (3a,b). The behavior of the temperature dependence of $\mathrm{Q}^{-1}$ values. The mechanical parameters given in Fig. $(4 \mathrm{a}, \mathrm{b})$ and $\mathrm{c}$ are controlled by the amount of the existing second phase $(\mathrm{Mg})$. 

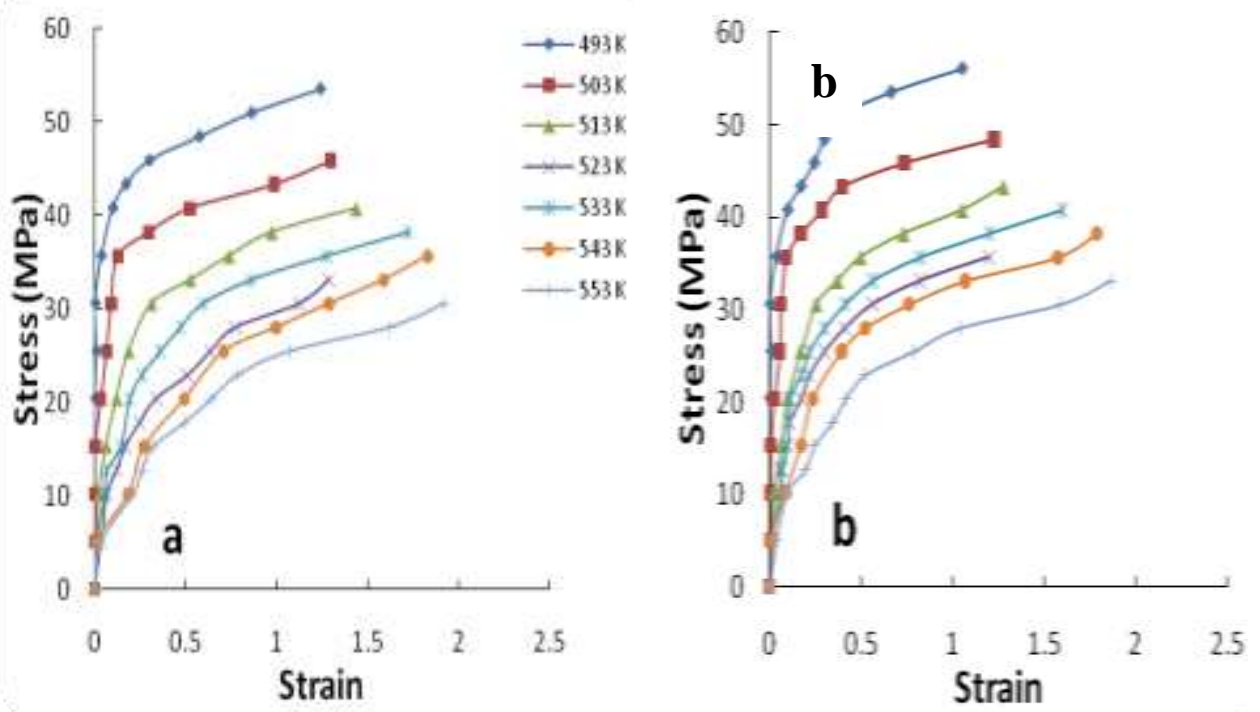

Fig. (5): Stress- strain curves of Al-5wt.\% Mg at different aging temperatures for: $\begin{array}{ll}\text { a) Slowly cooled samples } \quad \text { b) Quenched samples } & \end{array}$

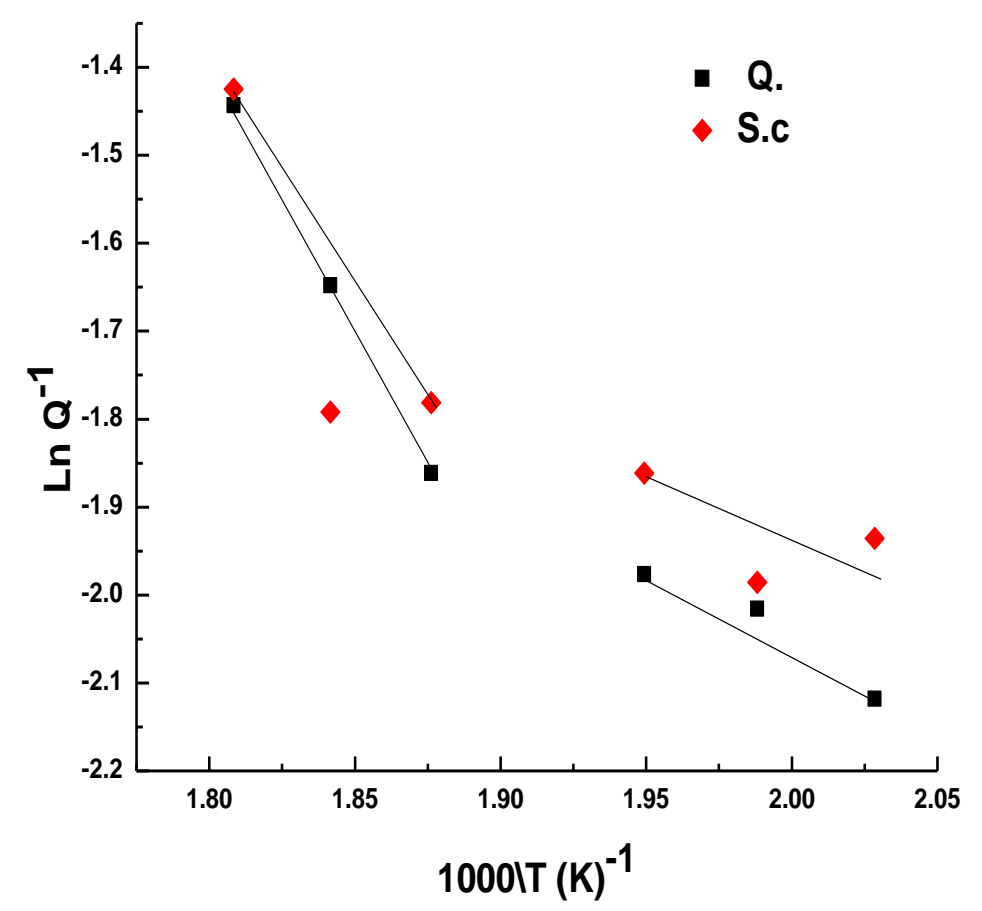

Fig. (6): Relation between $\ln \mathrm{Q}^{-1}$ and 1000/T for Al-5wt.\%Mg alloy. 


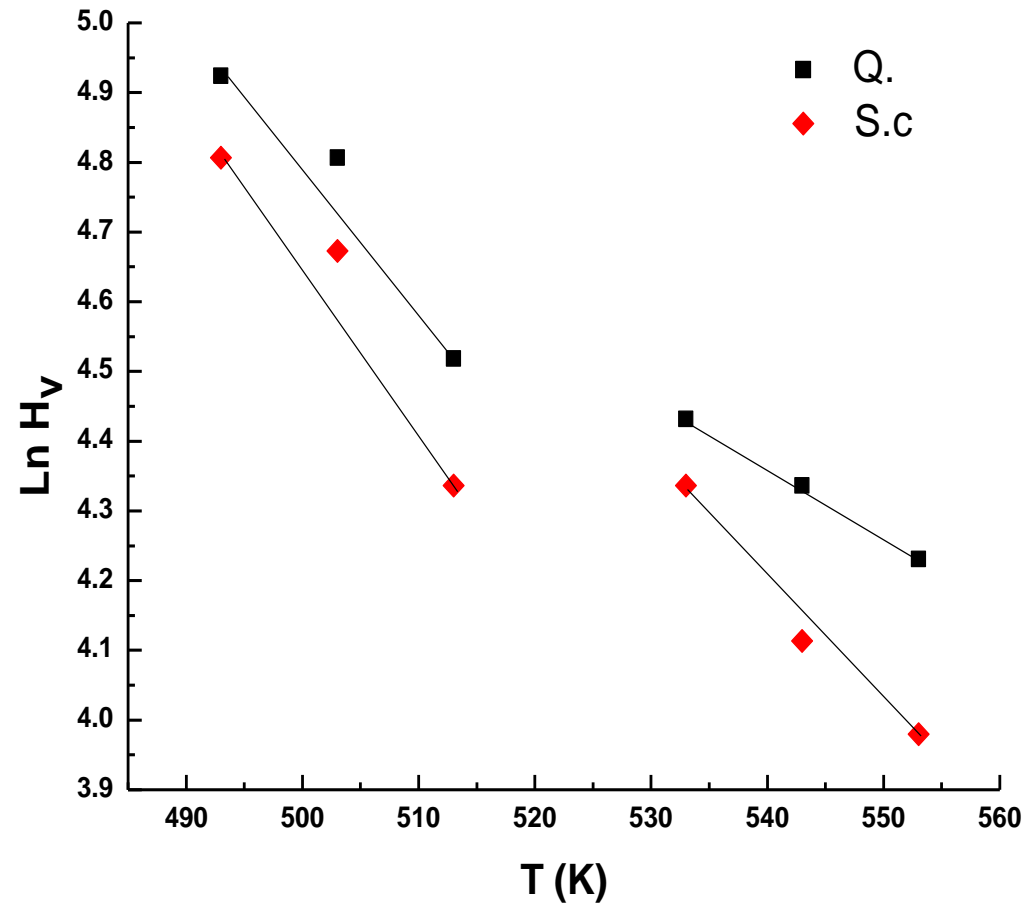

Fig. (7): Relation between $\ln \mathrm{H}_{\mathrm{v}}$ and $\mathrm{T}(\mathrm{K})$.

According to equation 3, Table (2) summarizes the present work in terms of both the softening coefficient $\alpha$ and the intrinsic hardness $\mathrm{H}_{\mathrm{o}}$ at $0 \mathrm{~K}$, obtained from the relation between $\ln \mathrm{H}_{\mathrm{v}}$ and aging temperature Fig.(7). As the defects in the quenched samples are more than those in the slowly cooled samples [18]. This leads to the lower values of $\mathrm{H}_{\mathrm{o}}$ and higher values of $\alpha$ for the slowly cooled samples than those for the quenched samples in the low temperature range.

Table (2)

\begin{tabular}{|c|c|c|c|c|}
\cline { 2 - 5 } \multicolumn{1}{c|}{} & \multicolumn{2}{c|}{$\boldsymbol{c}$} & \multicolumn{2}{c|}{$\mathbf{H}_{\mathbf{0}}$} \\
\cline { 2 - 5 } \multicolumn{1}{c|}{} & Before & After & Before & After \\
\hline Q & 0.002 & 0.01 & 16.42 & 13.82 \\
\hline S.C. & 0.0023 & 0.017 & 14.94 & 9.781 \\
\hline
\end{tabular}

In the high temperature range, $\alpha$ showed a constant value of 0.002 , which is higher than the values obtained in the low temperature range. This may be 
due to the dissolution of the $\alpha$-rich particles and the homogenization in the alloy. The different values of $\mathrm{H}_{\mathrm{o}}$ in Table 2, suggest that the history of heat treatment regime applied to the slowly cooled samples which have different components, i.e., of initial different states, than those of the quenched samples should lead to final different states at $0 \mathrm{~K}$, if reached, with different characteristics rather than common single state as wrongly may be expected at $0 \mathrm{~K}$.

The activation energy, Q, controlling the change of the mechanical parameters of the tested samples, is obtained from an Arrhenius - type relation, [22] of the form

$$
\mathrm{Q}^{-1}=\text { const. } \exp (\mathrm{Q} / \mathrm{KT})
$$

where $\mathrm{Q}$ is the activation energy $(\mathrm{kJ} / \mathrm{mol}$.) and $\mathrm{K}$ the Boltzman constant. From the slopes of the straight lines relating $\ln \mathrm{Q}^{-1}$ and 1000/T, given in Fig.6, the values of $\mathrm{Q}$ were found to be 17.33 and $59.184 \mathrm{~kJ} / \mathrm{mol}$ for annealed and quenched samples.

\section{Conclusions}

From the experimental results it could be concluded that

1. The mechanical properties of $\mathrm{Al}-5 \mathrm{wt} . \% \mathrm{Mg}$ alloy were strongly affected by heat treatment during preparation as well as quenching rate.

2. The values of the dynamic elastic Young's modulus Y and Vickers hardness $\mathrm{H}_{\mathrm{v}}$ of the quenched samples were higher than those of the slowly cooled samples.

3. The presence of the intermediate hard inclusions $\mathrm{Al}_{3} \mathrm{Mg}_{2}, \mathrm{Al}_{2} \mathrm{Mg}, \mathrm{Al}_{12} \mathrm{Mg}_{17}$ increased the measured dynamic elastic Young's modulus $\mathrm{Y}$ and Vickers hardness $\mathrm{H}_{\mathrm{v}}$ at lower temperature.

4. The measured $\mathrm{Q}^{-1}$ values of the slowly cooled samples are higher than those of the quenched samples.

\section{References}

1. W. Blum, High-temperature deformation and creep of crystalline solids, in Materials Science and Technology, Plastic deformation and fracture of materials, eds. Cahn, R.W. , Haasen, P. and Kramer, E.J., VCH Publishers, Weinheim, Germany, ( 1993).

2. T. H. Muster, Ae. Hughes, J. Electrchem. Soc. 153, B474 (2006).

3. O. Lunder, J. E. Lein. T. K. Aune, K. Nisancioglu, Corrosion, 45, 741 (1989) 
4. J. R. Davies, Corrosion of Aluminum and Aluminum Alloys, ASM International, Materials, Park, OH, (1999).

5. D. Sampath et al., Mater. Sci. Forum, 331, 1089 (2000).

6. A.V. Dobormyslove, L.I. Kamarova, M.F. Kamarova, Phys. Met. Metall. 43, 1228 (1977).

7. T. Sato, A. Kamio, Mater. Sci. Eng, A 146, 161 (1991).

8. L.F. Mondolfo, Aluminium Alloys: Structure and properties, Butterworths, London, (1976).

9. S. Samson, The crystal structure of the phase $\beta$ Mg2Al3, Acta. Cryst., vol. 19, 401 (1965).

10. M. A. Mahmoud, M. Sobhy, A.F. Abd El-Rehim, R. M. Abdel Rahman, Physica, B 405, 3616 (2010).

11. J. L. Daves, wve progration in solids and fluids (springner- verlag, new York), 8 (1988).

12. F. Abd El-Salam, A.M. Abd El-Khalek, R.H. Nada, M.R. Nagy and R. Abd El-Haseeb, Materials Science and Engineering, A 506, 135 (2009).

13. A.Y. Malkin, A. A. Askadsky, V.V. Kovriga, and A.E. Chalykh, Experimental Methods of polymer Physics (Mir Publishers, Moscow), 213 (1983).

14. F. Abd El-Salam, R.H. Nada, A.M. Abd El-Khalek, physica, B 292, 71 (2000).

15. H.Y. Zahran, MSc. Thesis, Physics Dept., Fac. Education Ain Shams Univ., 32 (2006).

16. M. Kerr, N. Chawla, Acta Materialia, 52, 4527 (2004).

17. F.Abd El-Salam, R.H.Nada, H. Abd El-Aziz, E.Abd El-Rheim, Egypt. J. Solids, 33, 1 (2010).

18. F. Abd El-Salam, A.M. Abd El-Khalek, R.H. Nada, A. Fawzy. Mat. Characterization, 59, 9 (2008).

19. H. Hosokawa, H. Iwasaki, T. Mori, M. Mabuchi, T. Tagata, K. Higashi, Acta Mater. 47, 1999 (1859).

20. F. Abd El-Salam, M.M. Mostafa, L.A. Wahab, M.T. Mostafa, Sh.M. Abd El-Aziz, Mat Sci and Eng. A 478, 71 (2008).

21. F. Abd El-Salam, A.M. Abd El-Khalek, R.H. Nada, L.A. Wahab, H.Y. Zahran, Mater. Sci. Eng. A 527, 1223 (2010). 